\title{
DESCRIPTION OF A NEW SPECIES OF THE GENUS PHANERoTOMA WESMAEL (HYMENOPTERA: BRACONIDAE) ALONG WITH A KEY TO INDIAN SPECIES
}

\author{
Zubair Ahmad ${ }^{1}$ and Shujauddin
}

\author{
${ }^{1}$ Department of Zoology, Section of Entomology, Aligarh Muslim University, Aligarh, Uttar Pradesh 202002, India
} E-mail: ${ }^{1}$ drazubair@yahoo.com

\begin{abstract}
A new species of the genus Phanerotoma is described. A key to the Indian species of this genus Phanerotoma is also given. A new replacement is proposed for P. indica Varshney \& Shujauddin.
\end{abstract}

\section{KEYWORDS}

Braconidae, Cheloninae, Hymenoptera, new name, new species, Phanerotoma hayati nom.nov., Phanerotoma syedi sp. nov.,

\section{Abbreviations}

AOL - Anterior-ocellar line; OOL - Ocello-ocular line; POL post-ocellar line; ØOD - Diameter of an ocellus; ZDAMU Zoology Department, Aligarh Muslim University.

The genus Phanerotoma Wesmael belongs to the subfamily Cheloninae of Braconidae. The genus is represented by seven species from India (Shenefelt, 1973; Zettel, 1990; Varshney \& Shujauddin, 1999). In the present work a new species is described from India and a key to Indian species of Phanerotoma is also provided. Achterberg (1993) has been followed for terminologies.

\section{Phanerotoma syedi sp. nov.}

(Figs. 1- 7)

Female: Length, $2.7 \mathrm{~mm}$; fore wing, $2.5 \mathrm{~mm}$.

Head: 0.9x maximum width of mesoscutum; frons and vertex transversely rugose with very finely granulate background sculpture; OOL:POL:AOL:ØOD =8:2:2:2 (Fig. 2); length of eye in dorsal view 2.0x temple (Fig. 2); face 1.5x as long as high, transversely rugose with very finely granulate background sculpture; clypeus $2.5 \mathrm{x}$ as broad as high, tubercles distinct (Fig. 1); malar space $0.5 \mathrm{x}$ basal width of mandible (Fig. 3); inner tooth of mandible short, shorter than half length of outer tooth (Fig. 1); antennae rather slender, 23-segmented; scapus 2.1x as long as broad, further segments gradually shortening, subapical segments submoniliform and as long as broad, apical segment $2 \mathrm{x}$ as long as broad (Fig. 6).

Mesosoma: Mesoscutum reticulo-granulate; scutellum granulate; propodeum rugose with a transverse carina. Forewing with pterostigma about $3.0 \mathrm{x}$ as long as broad and about $0.8 \mathrm{x}$ as long as 1-R1(Fig. 5); vein 3-SR and SR1 straight (Fig. 5); vein 2-SR bent (Fig. 5); vein r emerging much beyond the middle of pterostigma and $0.15 \mathrm{x}$ as long as 3-SR (Fig. 5); vein $\mathrm{m}$-cu $3 \mathrm{x}$ as long as vein $\mathrm{r}$ (Fig. 5); 2-SR+M distinct (Fig. 5). Mid tibia with indistinct bluster; hind tibia $4.0 \mathrm{x}$ as long as broad and about as long as hind femur; hind basitarsus $0.7 \mathrm{x}$ as long

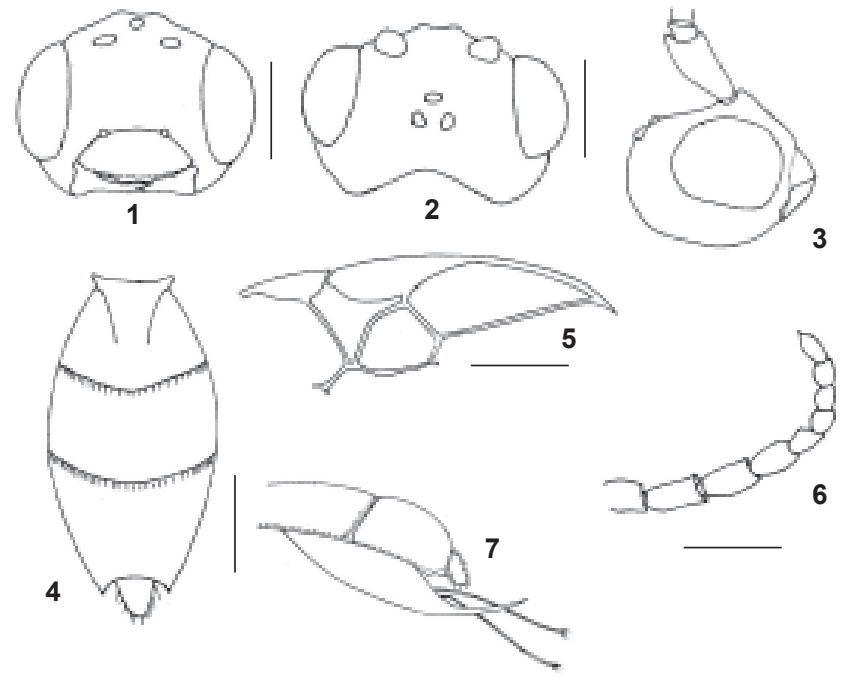

Figures 1-7. Phanerotoma syedi sp. nov., (female) 1 - Frontal head; 2 - Dorsal head; 3 - Lateral head; 4 - Dorsal metasoma; 5 - Apical fore wing;

6 - Subapical antennal segments; 7 - Lateral metasoma. Scale $=1-4 \& 7-1.0 \mathrm{~mm} ; 5-6-0.5 \mathrm{~mm}$

as remaining tarsal segments.

Metasoma: Shape of metasoma moderately elongate (Fig. 4); first and second tergite longitudinally rugos-striate; lateral converging carinae of tergite one on basal half; tergite three reticulate rugose, emarginated with sharp protruding corners latero-apically (Fig.4); ovipositor sheaths very long and thick (Fig.7); hypopygium abberent because of the presence of long apical spine (Fig.7).

Colour: Yellowish brown; palpi, fore and mid coxae whitish; apical half of hind tibia, third tergite and tips of mandible dark brown; stemmaticum black; wings hyaline, pterostigma dark brown, venetaion yellowish to yellowish brown.

Male: Unknown

\section{Material examined:}

Holotype: Female, INDIA: Uttar Pradesh: Etawa, 30. 4. 2002, Coll. Shamim Ahmad (ZDAMU).

Paratypes, $2 \mathrm{~F}$ with the same data as Holotype.

\section{Distribution:}

India: Uttar Pradesh. 


\section{Etymology:}

The species named after Sir Syed Ahmad Khan, founder of Aligarh Muslim University, Aligarh.

\section{Remarks:}

Phanerotoma syedi sp. nov. is allied to the Palaearctic species, P. bilinea (Lyle) (Achterberg, 1990) but differs for having subapical segments submoniliform (subapical segments rather slender in bilinea); first and second tergite longitudinally rugosstriate and third tergite raticulate rugose (first and second tergite coarsely irregularly rugose and third tergite rather matt in bilinea).

\section{Phanerotoma hayati nom.nov.}

Phanerotoma (Phanerotoma) indica Varshney \& Shujauddin, 1999: 260-262.

Preoccupied by Phanerotoma indica Zettel,1990.

\section{Distribution:}

India: Uttar Pradesh.

\section{Etymology:}

The species is renamed after Prof. M. Hayat, Aligarh Muslim University, Aligarh for his valuable contribution to the parasitic hymenoptera.

\section{REFERENCES}

Achterberg, C. Van. (1990). Revision of the Western Palaearctic Phanerotomini (Hymenoptera: Braconidae). Zoologische Verhandelingen 255: 1-160.

Achterberg, C. Van. (1993). Illustrated key to the subfamilies of the Braconidae (Hymenoptera: Ichneumonoidea). Zoologische Verhandelingen 283: 1-189.

Fahringer, J. (1932). Zwei new Braconidenarten als Feinde einer MordraupeZ. angew. Ent. 19:144-146.

Shenefelt, R.D. (1973). Hymenopterorum Catalogus. (Nov. ed.) Part 10, Braconidae 6: 813-936.

Varshney, K. \& Shujauddin. (1999). Two new species of the genus Phanerotoma Wesmael (Hymenoptera: Braconidae) from India. Record of zoological survey of India 97: 259-263.

Zettel, H. (1990). Die Phanerotoma - Arten des indischen subkontinentes (Insecta: Hymenoptera: Braconidae: Cheloninae) Reichenbachia 27: 147158.

\section{ACKNowledgement}

The authors are thankful to Professor M. Hayat for reviewing the manuscript and offering useful suggestions.

\section{Key to the Indian species of Phanerotoma*}

1. Hypopygium with very long apical spine [OOL:POL: $A O L: \varnothing O D=8: 2: 2: 2]$ Hypopyguim without such a long apical spine.......

2

P. indica Zettel

3

Ocelli small, OOL always greater than two ØOD; m-cu different........

3. Metasoma short and broad, shorter than the mesosoma at most $1.65 \mathrm{x}$ as long as broad Metasoma much slender

4. Fore wing with vein 2-SR distinctly curved. Fore wing with vein $2-S R$ almost straight

5. Fore wing with vein $3-\mathrm{SR}, 1.27 \mathrm{x}$ as long as vein $r$; metasoma of female at least $2.0 \mathrm{x}$ as long as broad Fore wing with vein $3-S R, 3.0 x$ as long as vein $r$; metasoma of female less than twice as long as broad.

6. Forewing with $\mathrm{m}$-cu interstitial; malar space $0.86 \mathrm{x}$ basal width of mandible; $\mathrm{OOL} 4.0 \mathrm{POL}$ Forewing with $\mathrm{m}-\mathrm{cu}$ antifurcal; malar space $0.43 \mathrm{x}$ basal width of mandible; OOL $3.3 \mathrm{x}$ POL
P. syleptae Zettel 4 P. nathani Zettel P. noyesi Zettel

P. agarwali Varshney \& Shujauddin P. hayati nom. nov.

* $P$. buckneri Fahringer is not included in the key. From the original description (noted from Zettel, 1990) it has the following characters: Temple $1 / 2$ eye width; head and thorax with setigerous punctures; carapace $1.8 \mathrm{x}$ as long as broad ; length $3 \mathrm{~mm}$. This species was described from material collected- Assam and Jharkhand.

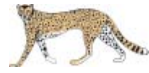

